\section{Swift action needed to close the skills gap in bioinformatics}

Sir - Bioinformatics, the manipulation and interpretation of the enormous volumes of data generated through research including genomics, proteomics, structural biology and dynamics of macromolecular assemblies, is a fastgrowing area. It will lead to a better understanding of biology and of disease, and an improved ability to design targeted drugs. But the skills in computer science and information technology required are in such short supply that the pace of advancement of some biological and biomedical sciences may soon be limited.

To quantify this skills gap in the United Kingdom, the Biotechnology and Biological Sciences Research Council (BBSRC) undertook an evidence-based review. It concluded that, relative to supply, demand for bioinformaticians is high in academic institutions and in the bioindustries. An approximate $60 \%$ increase in staff numbers is needed immediately in the (nonmedical) bioscience academic sector, and an approximate $45 \%$ increase is needed in large pharmaceutical companies. This situation will clearly become exacerbated with advances in genomics research and postgenomics.

Various training options, ranging from short courses to senior fellowships, need to be introduced or increased to address the skills gap. Diversity of options and of sponsors will ensure the best results. The BBSRC has increased by $60 \%$ the number of places sponsored on masters courses in bioinformatics and increased by a factor of two the number of $\mathrm{PhD}$ places. It is also introducing two bioinformatics summer schools for up to 60 staff and students a year.

The UK Medical Research Council (MRC) has also introduced training schemes in bioinformatics to support MSc and $\mathrm{PhD}$ studentships, as well as fellowships. In addition the UK research councils (BBSRC, MRC, Engineering and Physical Sciences Research Council, Natural Environment Research Council and Particle Physics and Astronomy Research Council) are to create at least two bioinformatics research groups, with training responsibilities, in computer science departments. Finally, the research councils are discussing future support with the Wellcome Trust.

The shortage of bioinformatics skills is not limited to the United Kingdom. The French 'génopôles', for example, will provide support for research and training in bioinformatics. Germany's research council, the Deutsche Forschungsgemeinschaft, has launched a programme to develop research and training centres in bioinformatics. The Swiss Institute for Bioinformatics has recently opened to provide research and teaching opportunities. Japan has announced a five-year plan to double funds for genome-related research, so requiring significant bioinformatics expertise, and the Australian government plans to develop a national genomics research capability and bioinformatics networks.

The US National Institutes of Health (NIH) has yet to respond to the recommendation of the working group on biomedical computing for the establishment of up to 20 national programmes of excellence. But the National Institute of General Medical Sciences is expected to launch a programme in bioinformatics training in the next few months. Some NIH institutes already run interdisciplinary training programmes in genome analysis and interpretation.

The first international bioinformatics summer school has been launched at the University of Magdeburg, Germany, with industrial sponsorship from the Volkswagen foundation. The International Society for Computational Biology is obtaining industrial sponsorship for international training fellowships in bioinformatics. This programme will enhance the in-house training offered by some companies.

Clearly, there is progress in the provision of bioinformatics training. Equally clearly, however, a quick glance at the scientific press reveals that there is an increasingly large volume of data that can only be fully understood and used through the application of bioinformatics skills.

Marlie MacLean, Colin Miles

Biotechnology and Biological Sciences Research

Council, Polaris House, North Star Avenue,

Swindon, Wiltshire SN2 1UH, UK

\section{France is still in the running on genomics}

Sir-As one of the main coordinators of the genomics report published by the French Academy of Sciences, I must express disappointment about your recent News article (Nature 400, 199; 1999). The title of the article, "France losing genome race", does not give a fair idea of the true spirit of our report.

The academy report attempts to give non-specialists an overview of the major current approaches and achievements in the field. It is true that the document underlines some weaknesses, gaps or shortcomings, for example in bioinformatics and in the development of start-up companies. But to state what could be improved by no means implies that the situation is hopeless. Our academy was asked to provide an independent vision of the state of genomics in France precisely in order to shed light on strengths and weaknesses. On the whole, it is our conclusion that our scientists have not lost the race.

A few weeks after our report was published, the government responded by giving genomics a high scientific and strategic priority.

François Gros

Institut de France, Académie des Sciences, 23 quai de Conti, 75006 Paris, France

\section{Japan's researchers could face more red tape}

Sir-National research institutes in Japan will experience a major reorganization before becoming semi-autonomous agencies in 2001 (Nature 398, 269; 1999). Although change may be necessary to improve efficiency, I do not have a rosy view of the reorganization. Scientists may have to struggle with even more red tape than at present.

This is what I predict will happen. Each ministry will try to retain power over the institutes that it controls at present. Preservation of power and budget is almost the basic principle of a government ministry. Existing institutes will be merged into a smaller number of research centres. It will be much easier for a ministry to control a smaller number of centres. But centralization may mean that individual institutes will lose their research independence. For scientists, centralization will certainly mean more tiers of administration above them. A research proposal must travel upwards through all the tiers of the hierarchy, winning approval at each stage. Having more tiers simply means more delay and more obstacles to clear. Politics and formalities rather than science may prevail in the decision-making process.

I believe that the hierarchical structure of the Japanese research system must be flattened to improve scientific performance and cut costs. Scientific performance will be the biggest concern for the new agencies, because it will be the criterion by which they are evaluated every three to five years, with the possibility that poor performers may be closed down.

The reorganization is planned as a means of cutting costs, and the agencies will be required to be much more efficient in spending money than the institutes are now. It is therefore crucial that the reorganization is done for the sake of performance and efficiency. If, instead, it is done for political reasons, the agencies will be laden with difficulties from the outset.

Kazuhiko Kobayashi

National Institute of Agro-Environmental Sciences, Ministry of Agriculture, Forestry and Fisheries, 3-1-1 Kannondai, Tsukuba, Ibaraki 305-8604, Japan 